\title{
Specificity of systolic anterior motion of anterior mitral leaflet for hypertrophic cardiomyopathy Prevalence in large population of patients with other cardiac diseases
}

\author{
BARRY J MARON, JOHN S GOTTDIENER, LOWELL W PERRY \\ From the Cardiology Branch, National Heart, Lung, and Blood Institute, National Institutes of Health, \\ Bethesda, Maryland; and the Department of Cardiology, Children's Hospital Medical Center, \\ Washington, DC, USA
}

SUMMARY The value of systolic anterior motion of the anterior mitral leaflet as a diagnostic marker for hypertrophic cardiomyopathy has been questioned because of its reported occurrence in other heart diseases. To determine the true specificity of systolic anterior motion for hypertrophic cardiomyopathy, 721 echocardiograms from patients with a wide variety of cardiac diseases were reviewed for its presence or absence under basal conditions. Systolic anterior motion of the anterior mitral leaflet was present in only $22(3.0 \%)$ of the 721 patients, giving a specificity of 97 per cent. It was most common in patients with d-transposition of the great vessels $(11$ of 51 , or $21 \%)$. With patients having transposition of the great vessels excluded from the analysis, the prevalence of systolic anterior motion of the anterior mitral leaflet was only 1.6 per cent (specificity $98 \%$ ). Of note, eight of the 11 patients with systolic anterior motion of the anterior mitral leaflet and diseases other than transposition of the great vessels had disproportionate thickening of the ventricular septum, making it exceedingly rare in a patient population with normal septal-free wall thickness ratios (prevalence $0.4 \%$; specificity $99 \%$ ). Hence, while systolic anterior motion is not pathognomonic of hypertrophic cardiomyopathy, it was an uncommon finding in a large population of patients with a variety of cardiac diseases; when present in such patients systolic anterior motion of the anterior mitral leaflet is usually associated with disproportionate septal thickening.

Systolic anterior motion of the anterior mitral leaflet (SAM) is a characteristic echocardiographic feature of patients with hypertrophic cardiomyopathy and obstruction to left ventricular outflow. ${ }^{1-6}$ Recently SAM has also been identified by echocardiography in a few patients with a variety of cardiac diseases other than hypertrophic cardiomyopathy. ${ }^{7-26}$

The finding of systolic anterior motion of the anterior mitral leaflet in such diseases has caused some investigators to suggest that it is a nonspecific finding and, hence, may not be a useful echocardiographic marker for patients with hypertrophic cardiomyopathy. ${ }^{19} 27$ Therefore, to determine the true specificity of SAM, echocardiograms from a large population of patients with congenital or acquired heart disease were analysed.

Received for publication 13 June 1980

\section{Selection and characterisation of patients}

The study group consisted of (1) consecutive patients with a wide variety of cardiac diseases other than hypertrophic cardiomyopathy who underwent echocardiographic studies at the National Heart, Lung, and Blood Institute between January 1975 and January 1978, and (2) all infants with d-transposition of the great vessels studied by echocardiography at the Children's Hospital National Medical Center, Washington, DC, between May 1974 and January 1979. The latter group of patients was included in the study group because of the reported frequent association of systolic anterior motion of the anterior mitral leaflet and transposition of the great vessels. ${ }^{7-13}$

The overall study group initially consisted of 775 patients; 54 were excluded because the mitral 206 
valve was not imaged adequately, and the final study group comprised 721 patients. Patients ranged in age from 1 day to 76 years (mean 40 years); 416 were male and 305 were female. Most patients had haemodynamically significant cardiac lesions, as evidenced by the fact that $247(66 \%)$ of the 375 patients with cardiac diseases amenable to surgical correction had undergone an operation subsequent to echocardiographic study. The cardiac diseases represented in the study population are summarised in Table 1.

\section{Subjects and methods}

Echocardiograms were performed under basal conditions with a $2.25 \mathrm{MHz}, 1.2 \mathrm{~cm}$ diameter or a $3.5 \mathrm{MHz}, 1.3 \mathrm{~cm}$ diameter transducer connected to either a modified Ekoline-20A or a Hoffrel 201 ultrasound unit and recorded continuously on light sensitive paper. Care was taken to orient the ultrasound transducer to enable both the anterior and posterior leaflets of the mitral valve to be recorded simultaneously.

In those patients with systolic anterior motion of the anterior leaflet of the mitral valve the position of the mitral valve in the left ventricular cavity was quantified by measuring the distance from the mitral valve (defined as the point of apposition of the anterior and posterior mitral leaflets at the onset of systole) to both the left ventricular endocardium of the ventricular septum and the endocardium of the left ventricular free wall. A mitral valve position index was computed by dividing the septal-mitral valve distance into the mitral valveposterior wall distance. ${ }^{28}$ The left ventricular outflow gradient (in $\mathrm{mmHg}$ ) was estimated from the echocardiogram by a method described elsewhere using a revised formula: gradient $=(1.8 \times$ obstruction index) $-53 .{ }^{5}$

Thickness of the ventricular septum was measured below the tips of the mitral valve leaflets just before atrial systole. Posterobasal left ventricular wall thickness was measured at the level of the tips of the mitral valve leaflets during the same phase of the cardiac cycle. Systolic anterior motion of the anterior leaflet of the mitral valve was defined as an abrupt anterior motion of the anterior mitral leaflet toward the ventricular septum beginning with the onset of systole, reaching its peak in mid-systole, and ending at or before the end of systole, ${ }^{1-514}$ and attaining a velocity exceeding that of the left ventricular posterior wall; hence, the peak anterior displacement of the anterior mitral leaflet occurred before that of the posterior wall. Instances in which the anterior mitral leaflet moved parallel to the
Table 1 Cardiac and systemic diseases in patients with or without systolic anterior motion of the anterior mitral leaflet (SAM)

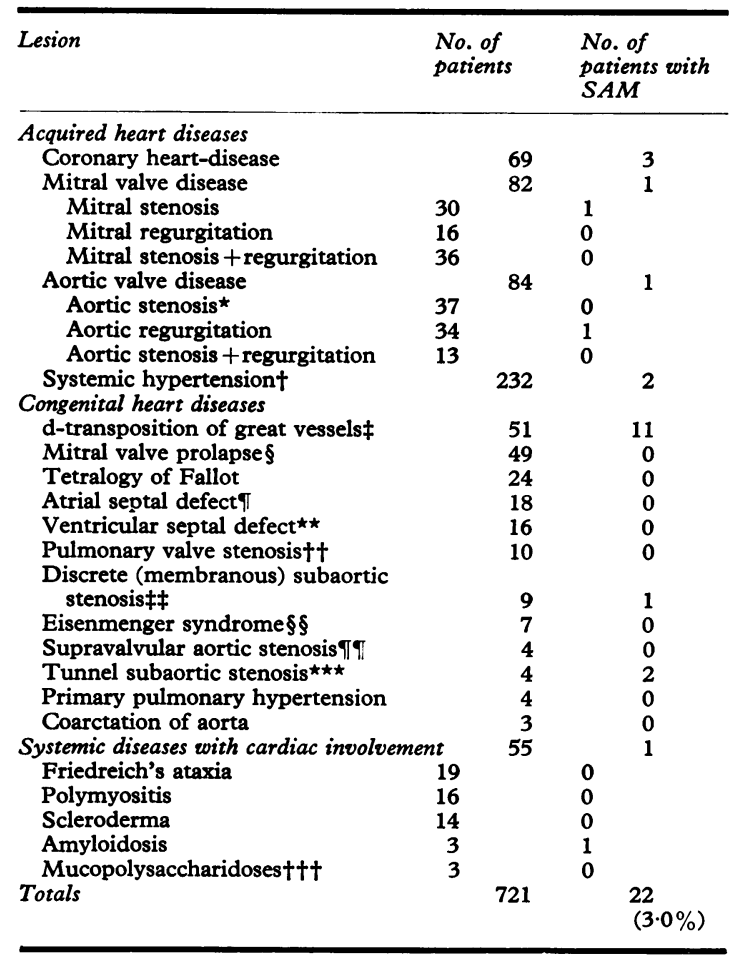

$\star$ Peak systolic gradients between left ventricle and systemic artery ranged from 40 to $135 \mathrm{mmHg}$ (average $88 \mathrm{mmHg}$ ).

tIncludes 133 patients on antihypertensive therapy at time of echocardiographic study and 99 patients who had such therapy discontinued for at least 3 weeks before study. At time of echocardiographic study systolic blood pressure ranged from 106 to $218 \mathrm{mmHg}$ (average $147 \mathrm{mmHg}$ ); diastolic blood pressure ranged from 68 to $150 \mathrm{mmHg}$ (average $95 \mathrm{mmHg}$ ).

‡Includes six patients with ventricular septal defect, 13 patients with pulmonary stenosis (valvular, subvalvular, or supravalvular), 13 patients with both ventricular septal defect and pulmonary stenosis, and 19 patients with neither ventricular septal defect nor pulmonary stenosis; of the 51 patients, 22 were studied by echocardiography after undergoing Mustard's operation and the remaining 29 had not undergone this operative procedure at time of echocardiographic study.

§Includes eight patients with significant mitral regurgitation.

TPulmonary to systemic flow ratios ranged from 1.5 to 4.4 (average 2.6).

$\star \star$ Pulmonary to systemic flow ratios ranged from 1.3 to $5 \cdot 4$ (average 2.4).

††Peak systolic gradients between right ventricle and pulmonary artery ranged from 25 to $115 \mathrm{mmHg}$ (average $64 \mathrm{mmHg}$ ).

$\ddagger \ddagger$ Peak systolic left ventricular outflow tract gradients ranged from 60 to $140 \mathrm{mmHg}$ (average $96 \mathrm{mmHg}$ ).

\$SIncludes six patients with ventricular septal defect and one patient with persistent ductus arteriosus.

โा Peak systolic gradients ranged from 30 to $140 \mathrm{mmHg}$ (average 70 $\mathrm{mmHg}$ ).

$\star \star \star$ Peak systolic left ventricular outflow tract gradients ranged from 110 to $150 \mathrm{mmHg}$ (average $128 \mathrm{mmHg}$ ).

t+†Includes one patient with type II (Hunter), one patient with type III (San Fillipo), and one patient with type IV (Schies) mucopolysaccharidoses. 
contour of the left ventricular free wall in systole ("pseudo-SAM"14) were not considered to be true abnormalities of mitral valve motion. Mitral valve prolapse was identified using the criteria of Popp et $a l .{ }^{29}$ and the technique of Weiss et al. ${ }^{30}$

\section{Results}

\section{VENTRICULAR WALL THICKNESS}

In 636 of the 721 echocardiograms, an accurate assessment of ventricular wall thicknesses could be made. Sixty-five $(10 \%)$ of the 636 patients had an abnormal ventricular septal to left ventricular free wall thickness ratio (that is $\geqslant 1.3$ ); ventricular wall thicknesses were symmetrical in the remainder (septal-free wall ratio $<1 \cdot 3$ ).

\section{ABNORMALITIES OF MITRAL VALVE MOTION}

Systolic anterior motion of the anterior mitral leaflet was present in $22(3.0 \%)$ of the 721 patients (Table 2), yielding a specificity ${ }^{\star}$ of 97 per cent. In 12 of these 22 patients the magnitude of systolic naterior motion of the anterior mitral leaflet was mild, as evidenced by the fact that the gradient estimated from the echocardiogram was zero. Cardiac catheterisation was performed (not simultaneous with the echocardiographic studies) in nine of these 12 patients; under basal conditions no or small gradients of 2 to $20 \mathrm{mmHg}$ were present in eight of these patients and a gradient of $40 \mathrm{mmHg}$ was present in the other parient. In 10 other study patients systolic anterior motion of the anterior mitral leaflet was marked as evidenced by the fact that a gradient of 5 to $100 \mathrm{mmHg}$ was estimated from the echocardiogram. Nine of these 10 patients had cardiac catheterisation and each had a left * Specificity is defined as the percentage of negative results in subjects without hypertrophic cardiomyopathy: True negative

True negative + false positive $\times 100$

Table 2 Clinical and echocardiographic findings in 22 patients with systolic anterior motion of the anterior mitral leaflet (SAM)

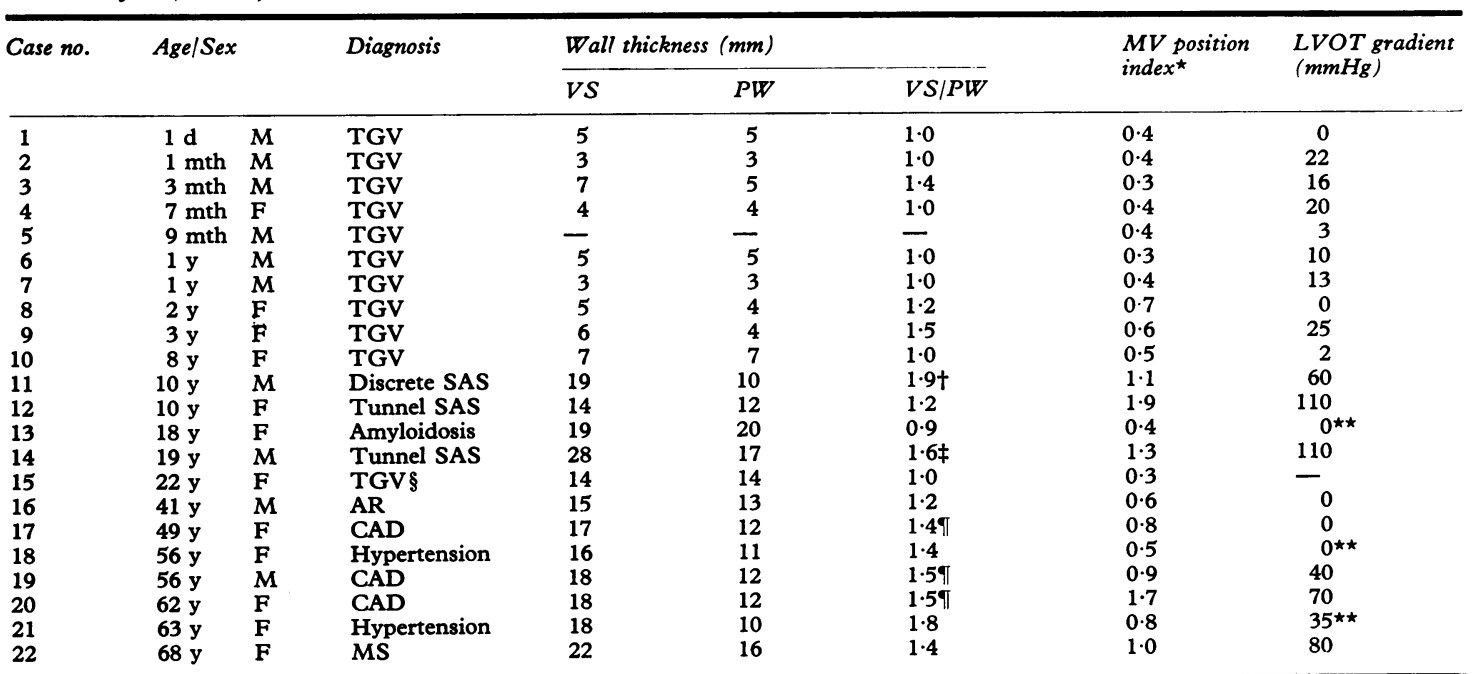

Abbreviations: AR, aortic regurgitation; AS, aortic stenosis; CAD, coronary artery disease; LVOT, left ventricular outflow tract; $M$ S, mitral stenosis; MV, mitral valve; PW, posterior left ventricular free wall; SAS, subaortic stenosis; TGV, d-transposition of the great vessels; VSD ventricular septal defect; VS/PW, ventricular septal to posterior left ventricular free wall thickness ratio.

${ }^{*}$ Mitral valve position in left ventricular cavity assessed from echocardiogram by previously described method ${ }^{28}($ normal $=<0.3)$.

tAbnormal septal-free wall ratio was manifestation of coexistent hypertrophic cardiomyopathy based on echocardiographic identificatior of asymmetric septal hypertrophy in a first degree relative.

¥Abnormal septal-free wall ratio was a manifestation of coexistent hypertrophic cardiomyopathy based on finding of severe disorganisation of cardiac muscle cells (involving $98 \%$ of relevant parts of tissue section) in ventricular septum at necropsy.

\$Associated with large ventricular septal defect; each other patient with transposition of great vessels had intact ventricular septum.

IAsocing al the posterior free wall thickness ratios in these three patients, ${ }^{24} 49$ that is, by echocardiography the posterior free wall was of normal thickness in diastole and also thickened normally in systole. The moderate degree of absolute ventricular septal thickening (17 to $18 \mathrm{~mm}$ ) present in these patients verified that the abnormal septal-free wall ratios were a result of disproportionate thickening of ventricular septum.

$\star \star$ Cardiac catheterisation not performed; estimation of left ventricular outflow gradient was made from the echocardiogram by a previously described method's.

-, Data not available. 
ventricular outflow tract gradient measured under basal conditions of 10 to $110 \mathrm{mmHg}$. In addition, in seven of these 10 patients with pronounced systolic anterior motion of the anterior mitral leaflet, the mitral valve was positioned far anteriorly in the left ventricular cavity (mitral valve position index $>0.60$ ); six of the 10 patients had disproportionate septal thickening (septal-free wall thickness ratio $\geqslant 1 \cdot 3$ ).

Systolic anterior motion of the anterior mitral leaflet was particularly common in patients with complete (d-) transposition of the great vessels, that is in $11(21 \%)$ of 51 such patients. Of the 11 patients with transposition of the great vessels who also had systolic anterior motion of the anterior mitral leaflet, eight were infants (2 years of age or younger), two were children aged 3 and 8 years, and one was a 22-year-old adult; six were found to have systolic anterior motion of the anterior mitral leaflet before undergoing Mustard's operation, and five had SAM identified after operation. Ten of the 11 patients with transposition of the great vessels and systolic anterior motion of the anterior mitral leaflet had an intact ventricular septum, but one had a large ventricular septal defect.

Hence, in this study group one-half of the patients with systolic anterior motion of the anterior mitral leaflet (11 of 22) had transposition of the great vesseis. The remaining 11 patients had a variety of other congenital or acquired cardiac lesions, including three with coronary artery disease, two with systemic hypertension, two with tunnel subaortic stenosis, and one each with discrete subaortic stenosis, mitral stenosis, aortic regurgitation, and amyloidosis. If the patients with transposition of the great vessels were excluded from the data analysis, then the prevalence of systolic anterior motion of the anterior mitral leaflet was only 1.6 per cent (11 of 670 patients), and the specificity was 98 per cent.

Of note, eight of these 11 patients with systolic anterior motion of the anterior mitral leaflet (and without transposition of the great vessels) had disproportionate septal thickening; two other patients had borderline thickness ratios of $1 \cdot 2$. Furthermore, of the six patients with pronounced systolic anterior motion of the anterior mitral leaflet (suggesting left ventricular outflow obstruction) but without transposition of the great vessels, five had disproportionate septal thickening.

In two of the eight patients with systolic anterior motion of the anterior mitral leaflet and septal-free wall ratio $\geqslant 1 \cdot 3$, the septal thickening was considered to be the result of coexistent hypertrophic cardiomyopathy; one of these patients had genetic transmission of asymmetric septal hypertrophylin
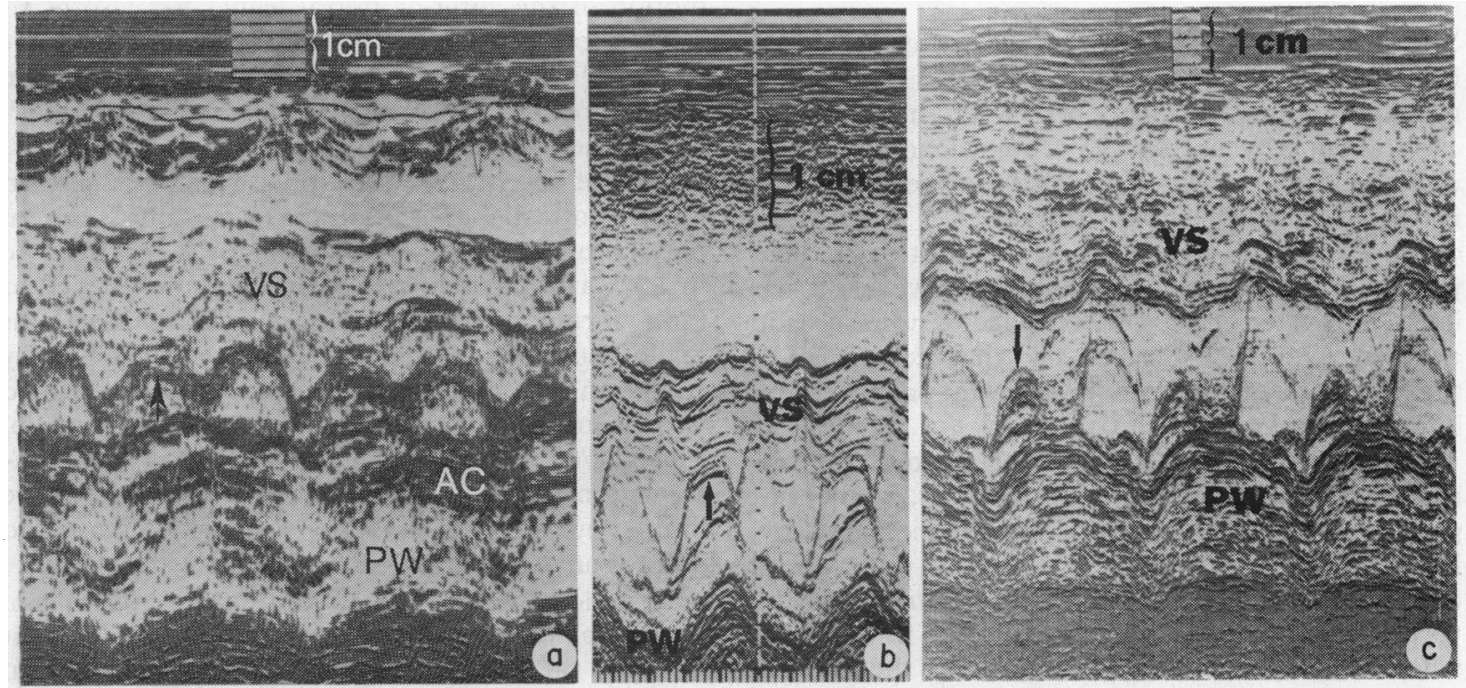

Fig. Illustrative echocardiograms showing systolic anterior motion of the anterior mitral leaflet in cardiac diseases other than hypertrophic cardiomyopathy. (a) Severe systolic anterior motion in a 68-year-old woman with mitral valve stenosis (after aortic valve replacement); (b) Severe systolic anterior motion in a 3-year-old infant with d-transposition of the great vessels; (c) Mild systolic anterior motion in an 18-year-old girl with cardiac amyloidosis and severe concentric left ventricular hypertrophy. $A C$, (mitral) annular calcification; VS, ventricular septum; $P W$, posterior left ventricular free wall; arrows indicate $S A M$ in each of the three panels. 
first degree relatives demonstrated by echocardiography ${ }^{31} 32$ and the other had severe disorganisation of cardiac muscle cells in the ventricular septum at necropsy. ${ }^{33-35}$ Because comprehensive familial echocardiographic studies were not performed in relatives of the other six patients with systolic anterior motion of the anterior mitral leaflet and abnormal septal-free wall ratio, it is not certain whether or not these six patients had coexistent hypertrophic cardiomyopathy. The presence, however, of a substantial dynamic left ventricular outflow gradient (35 to $80 \mathrm{mmHg}$ ) was suggestive of an obstructive hypertrophic cardiomyopathy in four of these six patients.

If those patients with systolic anterior motion and an abnormal septal-free wall ratio are excluded from the data analysis, the prevalence of SAM in a large population of patients with a wide variety of heart diseases producing symmetric wall thicknesses (exclusive of transposition of the great vessels) proved to be exceedingly small, that is 0.4 per cent (specificity of $99 \%$ ).

Mitral valve prolapse was present in $37(5.5 \%)$ of the 672 patients in this study who had a primary cardiac diagnosis other than mitral valve prolapse; one of these 37 patients with prolapse of the posterior mitral leaflet had associated systolic anterior motion of the anterior mitral leaflet.

\section{Discussion}

Systolic anterior motion of the anterior mitral leaflet is recognised as a characteristic echocardiographic finding in patients with hypertrophic cardiomyopathy and outflow obstruction. ${ }^{1-6}$ Most available data ${ }^{2-5} 36$ show that in its severe form SAM is, in fact, responsible for the left ventricular outflow tract narrowing and subaortic gradient present in such patients; recently, however, it has been suggested that the chordae tendineae and even the papillary muscles also may contribute to the dynamic obstruction present in patients with hypertrophic cardiomyopathy. ${ }^{37-40}$

The present study shows that systolic anterior motion of the anterior mitral leaflet, while not pathognomonic for hypertrophic cardiomyopathy, is an uncommon finding (that is $3 \%$ ) under basal conditions in a large population of patients with a variety of other cardiac diseases. The infrequency with which systolic anterior motion of the anterior mitral leaflet occurs in the absence of hypertrophic cardiomyopathy makes SAM a highly specific (that is $97 \%$ ) and useful marker for patients with hypertrophic cardiomyopathy and obstruction to left ventricular outflow. This is particularly true regarding severe degrees of SAM which, while common in patients with hypertrophic cardiomyopathy and outflow obstruction, were exceedingly uncommon in the present study group of patients with other cardiac diseases (10 of 721 patients or $1.3 \%$ ). On the other hand, systolic anterior motion of the anterior mitral leaflet cannot be considered a particularly sensitive marker for hypertrophic cardiomyopathy. This is necessarily true because while severe forms of SAM are almost invariably present in patients with obstruction to left ventricular outflow, SAM of this magnitude does not occur in patients without outflow obstruction (who represent a sizeable proportion of all patients within the wide disease spectrum of hypertrophic cardiomyopathy ${ }^{32}$ ).

Of note, in this study group systolic anterior motion of the anterior mitral leaflet was particularly common $(21 \%)$ in the subgroup of 51 patients (primarily infants) with transposition of the great vessels; its relatively common occurrence in transposition of the great vessels has been reported previously by other investigators. ${ }^{7-911-13}$ In addition to transposition of the great vessels, systolic anterior motion of the anterior mitral leaflet was also identified in a diverse variety of other cardiac diseases, including coronary heart disease, systemic hypertension, tunnel subaortic stenosis, discrete (membranous) subaortic stenosis, aortic regurgitation, mitral stenosis, and amyloidosis. Though not present in the present study group, systolic anterior motion of the anterior mitral leaflet has also occasionally been reported in patients with aortic valve stenosis ${ }^{41}$ and after aortic valve replacement, ${ }^{42}$ in coarctation of the aorta, ${ }^{26}$ ventricular aneurysm, ${ }^{43}$ hypovolaemic shock, ${ }^{19}$ glycogen storage (Pompe's) disease of the heart, ${ }^{21}$ Friedreich's ataxia, ${ }^{22}$ and in infants of diabetic mothers. ${ }^{44-46}$ The patient population in the present study was selected to include a mixture of the more common as well as rarer forms of cardiac disease. No attempt was made, however, to include an analysis of every condition that has been reported to be associated with systolic anterior motion of the anterior mitral leaflet. For example, though SAM has been described in patients without cardiac hypertrophy ${ }^{14}$ we limited our study to patients with heart disease and did not analyse normal subjects.

Systolic anterior motion of the anterior mitral leaflet was present in a substantial proportion (that is $30 \%$ ) of patients in this study with abnormal septal-free wall ratios (the vast majority of which had no apparent evidence of primary hypertrophic cardiomyopathy and probably represented secondary disproportionate ventricular septal thickening). ${ }^{47}$ Conversely, systolic anterior motion of the anterior mitral leaflet was a particularly un- 
common finding in our patients with symmetric (concentric) ventricular wall thicknesses (septal-free wall ratio $<1.3$ ), that is prevalence of 0.4 per cent and specificity of 99 per cent. Therefore, systolic anterior motion of the anterior mitral leaflet appears to be a much less specific marker for hypertrophic cardiomyopathy in the presence of disproportionate septal thickening than in the presence of concentric hypertrophy.

Our data also show that when severe systolic anterior motion occurs in patients with diseases other than hypertrophic cardiomyopathy, SAM is usually responsible for left ventricular outflow tract obstruction. Of the 10 patients with severe forms of SAM (that is sufficient to produce an estimated gradient by echocardiography) who underwent cardiac catheterisation, nine had outflow gradients of 10 to $110 \mathrm{mmHg}$ measured. In the majority of these patients with severe systolic anterior motion of the anterior mitral leaflet and documented outflow obstruction the anterior mitral leaflet was displaced anteriorly in the left ventricular cavity at the onset of systole and asymmetric septal hypertrophy was present. In hearts with such a geometric configuration, the narrowed left ventricular outflow tract may have created the necessary hydrodynamic forces so that the velocity of blood passing between the hypertrophied ventricular septum and anterior mitral leaflet sucked the mitral leaflet forward by a Venturi effect. ${ }^{28} 48$

\section{References}

1 Shah PM, Gramiak R, Kramer DH. Ultrasound localization of left ventricular outflow obstruction in hypertrophic obstructive cardiomyopathy. Circulation 1969; 40: 3-11.

2 Shah PM, Gramiak R, Adelman AG, Wigle ED. Role of echocardiography in diagnostic and hemodynamic assessment of hypertrophic subaortic stenosis. Circulation 1971 ; 44: 891-8.

3 Shah PM, Gramiak R, Adelman AG, Wigle ED. Echocardiographic assessment of the effects of surgery and propranolol on the dynamics of outflow obstruction in hypertrophic subaortic stenosis. Circulation 1972; 45: 516-21.

4 Popp RL, Harrison DC. Ultrasound in the diagnosis and evaluation of idiopathic hypertrophic subaortic stenosis. Circulation 1969; 40: 905-14.

5 Henry WL, Clark CE, Glancy DL, Epstein SE. Echocardiographic measurement of the left ventricular outflow gradient in idiopathic hypertrophic subaortic stenosis. $N$ Engl f Med 1973; 288: 989-93.

6 Pridie RB, Oakley CM. Mechanism of mitral regurgitation in hypertrophic obstructive cardiomyopathy. Br Heart f 1970; 32: 203-8.

7 Nanda NC, Gramiak R, Manning JA, Lipchik EO. Echocardiographic features of subpulmonic obstruc- tion in dextrotransposition of the great vessels. Circulation 1975; 51: 515-21.

8 Silverman NH, Payot M, Stanger P, Rudolph AM. The echocardiographic profile of patients after Mustard's operation. Circulation 1978; 58: 1083-93.

9 Park SC, Neches WH, Zuberbuhler JR, Mathews RA, Lenox CC, Fricker FJ. Echocardiographic and hemodynamic correlation in transposition of the great arteries. Circulation 1978; 57: 291-8.

10 Sahn DJ, Terry R, O'Rourke R, Leopold G, Friedman WF. Multiple crystal cross-sectional echocardiography in the diagnosis of cyanotic congenital heart disease. Circulation 1974; 50: 230-8.

11 Aziz KU, Paul MH, Muster AJ. Echocardiographic localization of interatrial baffle after Mustard operation for dextrotransposition of the great arteries. $\mathrm{Am} \mathcal{F}$ Cardiol 1976; 38: 67-72.

12 Aziz KU, Paul MH, Muster AJ. Echocardiographic assessment of left ventricular outflow tract in dtransposition of the great arteries. Am $\mathcal{F}$ Cardiol 1978; 41: 543-51.

13 Aziz KU, Paul MH, Idriss FS, Wilson AD, Muster AJ. Clinical manifestations of dynamic left ventricular outflow tract stenosis in infants with d-transposition of the great arteries with intact ventricular septum. Am F Cardiol 1979; 44: 290-7.

14 Mintz GS, Kotler MN, Segal BL, Parry WR. Systolic anterior motion of the mitral valve in the absence of asymmetric septal hypertrophy. Circulation 1978; 57: 256-63.

15 Rossen RM, Goodman DJ, Ingham RE, Popp RL. Echocardiographic criteria in the diagnosis of idiopathic hypertrophic subaortic stenosis. Circulation 1974; 50: 747-51.

16 Boughner DR, Rakowski H, Wigle D. Mitral valve systolic anterior motion in the absence of hypertrophic cardiomyopathy (abstract). Circulation 1978; 57, suppl II: II-235.

17 Savage DD, Drayer JIM, Henry WL, et al. Echocardiographic assessment of cardiac anatomy and function in hypertensive subjects. Circulation 1979; 59: 623-32.

18 Toshima H, Koga Y, Yashioka H, Akiyoshi T, Kimura N. Echocardiographic classification of hypertensive heart disease. A correlative study with clinical features. $\mathcal{F} p n$ Heart $\mathcal{f}$ 1975; 16: 377-93.

19 Bulkley BH, Fortuin NJ. Systolic anterior motion of the mitral valve without asymmetric septal hypertrophy. Chest 1976; 69: 694-6.

20 Davis RH. Feigenbaum H, Chang S. Konecke LL, Dillon JC. Echocardiographic manifestations of discrete subaortic stenosis. Am f Cardiol 1974; 33: 277-80.

21 Rees A, Elbl R, Minhas K, Solinger R. Echocardiographic evidence of outflow tract obstruction in Pompe's disease (glycogen storage disease of the heart). Am f Cardiol 1976; 37: 1103-6.

22 Gattiker HF, Davignon A, Bozio A, et al. Echocardiographic findings in Friedreich's ataxia. Can $\mathcal{F}$ Neurol Sci 1976; 3: 329-32.

23 Maron BJ, Redwood DR, Roberts WC, Henry WL, 
Morrow AG, Epstein SE. Tunnel subaortic stenosis. Left ventricular outflow tract obstruction produced by fibromuscular tubular narrowing. Circulation 1976; 54: 404-16.

24 Maron BJ, Savage DD, Clark CE, et al. Prevalence and characteristics of disproportionate ventricular septal thickening in patients with coronary artery disease. Circulation 1978; 57: 250-6.

25 Maron BJ, Gottdiener JS, Roberts WC, Hammer WJ, Epstein SE. Nongenetically transmitted disproportionate ventricular septal thickening associated with left ventricular outflow obstruction. Br Heart f 1979 ; 41 : 345-9.

26 Scovil JA, Nanda NC, Gross CM, et al. Echocardiographic studies of abnormalities associated with coarctation of the aorta. Circulation 1976; 53: 953-6.

27 Bulkley BH. Idiopathic hypertrophic subaortic stenosis afflicted: idols of the cave and the marketplace. Am f Cardiol 1977; 40: 476-9.

28 Henry WL, Clark CE, Griffith JM, Epstein SE. Mechanism of left ventricular outflow obstruction in patients with obstructive asymmetric septal hypertrophy (idiopathic hypertrophic subaortic stenosis). Am $\mathcal{f}$ Cardiol 1975; 35: 337-45.

29 Popp RL, Brown OR, Silverman JF, Harrison DC. Echocardiographic abnormalities in the mitral valve prolapse syndrome. Circulation 1975; 49: 428-33.

30 Weiss AN, Mimbs JW, Ludbrook PA, Sobel BE. Echocardiographic detection of mitral valve prolapse. Exclusion of false positive diagnosis and determination of inheritance. Circulation 1975; 52: 1091-6.

31 van Dorp WG, ten Cate FJ, Vletter WB, Dohmen H, Roelandt J. Familial prevalence of asymmetric septal hypertrophy. Eur $\mathcal{f}$ Cardiol 1976; 4: 349-57.

32 Clark CE, Henry WL, Epstein SE. Familial prevalence and genetic transmission of idiopathic hypertrophic subaortic stenosis. $N$ Engl $\mathscr{f}$ Med 1973; 289: 709-14.

33 Maron BJ, Roberts WC. Quantitative analysis of cardiac muscle cell disorganization in the ventricular septum of patients with hypertrophic cardiomyopathy. Circulation 1979; 59: 689-706.

34 Ferrans VJ, Morrow AG, Roberts WC. Myocardial ultrastructure in idiopathic hypertrophic subaortic stenosis. A study of operatively excised left ventricular outflow tract muscle in 14 patients. Circulation 1972; 45: 769-92.

35 Teare D. Asymmetrical hypertrophy of the heart in young adults. $\mathrm{Br}$ Heart $\mathcal{f} 1958 ; 20$ : 1-8.

36 Rakowski H, Gilbert BW, Drobac M, Pollick C, Boughner D, Wigle ED. Obstructive versus nonobstructive SAM: a crucial distinction (abstract). Am $f$ Cardiol 1980; 45: 491.

37 Rodger JC. Motion of mitral apparatus in hypertrophic cardiomyopathy with obstruction. Br Heart $\mathcal{G}$ 1976; 38: 732-7.
38 Tajik AJ, Seward JB, Hagler DJ. Detailed analysis of hypertrophic obstructive cardiomyopathy by wideangle two-dimensional sector echocardiography (abstract). Am F Cardiol 1979; 43: 348.

39 Gardin JM, Stephanides LM, Kordecki S, Talano JV. Systolic anterior motion in the absence of asymmetrical septal hypertrophy: a buckling phenomenon of the chordae tendinae (abstract). Circulation 1978; 57, suppl II: II-121.

40 Gehrke J, Goodwin JF. The significance of systolic anterior motion (SAM) on the mitral valve echo pattern in hypertrophic cardiomyopathy. Clin Cardiol 1978; 1: 152-62.

41 Feizi O, Emanuel R. Echocardiographic spectrum of hypertrophic cardiomyopathy. Br Heart $\mathcal{f}$ 1975; 37: 1286-302.

42 Thompson $R$, Ahmed $M$, Pridie $R$, Yacoub $M$. Hypertrophic cardiomyopathy after aortic valve replacement. Am f Cardiol 1980; 45: 33-41.

43 Criley JM, Lennon PA, Abassi AS, Blaufuss AH. Hypertrophic cardiomyopathy. In: Levine $\mathrm{HJ}$, ed. Clinical cardiovascular physiology. New York: Grune \& Stratton, 1976: 771-827.

44 Gutgesell HP, Mullins CE, Gillette PC, Speer M, Rudolph AJ, McNamara DG. Transient hypertrophic subaortic stenosis in infants of diabetic mothers. F Pediatr 1976; 89: 120.

45 Gutgesell HP, Speer ME, Rosenberg HS. Characterization of the cardiomyopathy of infants of diabetic mothers. Circulation 1980; 61: 441-50.

46 Way GL, Wolfe RR, Eshaghpour E, Bender RL, Jaffe RB, Ruttenberg HD. The natural history of hypertrophic cardiomyopathy in infants of diabetic mothers. F Pediatr 1979; 95: 1020-5.

47 Maron BJ, Clark CE, Henry WL, et al. Prevalence and characteristics of disproportionate ventricular septal thickening in patients with acquired or congenital heart diseases: echocardiographic and morphologic findings. Circulation 1977; 55: 489-96.

48 Wigle ED, Adelman AG, Silver MD. Pathophysiological considerations in muscular subaortic stenosis. In: Wolstenholme GEW, O'Connor $M$, eds. Hypertrophic obstructive cardiomyopathy, London, J \& A Churchill, 1971: 63-76.

49 Stern A, Kessler KM, Hammer WJ, Kreulen TH, Spann JF. Septal-free wall disproportion in inferior infarction: the echocardiographic differentiation from hypertrophic cardiomyopathy. Circulation 1978; 58: 700-6.

Requests for reprints to Dr Barry J Maron, Cardiology Branch, Building 10, Room 7B-15, National Heart, Lung, and Blood Institute, National Institutes of Health, Bethesda, Maryland 20205, USA. 